\title{
Improving the Estimation Efficiency of Jordanian Central Government Budget Depending on Information Based on Final Account Statement-Field Study
}

\author{
Hamdan Moh'D Al-Hiyasat ${ }^{1}$ \\ ${ }^{1}$ Accounting Dept, Faculty of Business and Finance, The World Islamic Sciences \& Education University, \\ Jordan \\ Correspondence: HamdanMoh'D Al-Hiyasat, Associate Professor, Accounting Department, Faculty of Business \\ and Finance, The World Islamic Sciences \& Education University, Jordan. E-mail: hamdan.hyasat@yahoo.com
}

Received: January 16, 2018

Accepted: March 10, 2018

Online Published: April 18, 2018

doi:10.5539/ijbm.v13n5p201

URL: https://doi.org/10.5539/ijbm.v13n5p201

\begin{abstract}
This study aims at improving the estimation efficiency of Jordanian central government budget depending on information based on final account statement. To achieve the aims of the study, a questionnaire was designed and handed to administrative and financial jobs in addition to workers as budget analyst workers among the study society consisting of the Ministry of Finance represented in general budget department as it is the responsible part of making the general budget for the government due to law number (58) for the year (2008). The researcher distributed (94) questionnaires to the members of the study sample, (63) have been regained that are valid to statistical analysis aims with a response ratio (\%67.02). Also, the statistical program of social science (SPSS) represented in descriptive statistics and (One Sample T-Test), (One Way ANOVA) and (Reliability Analysis Alpha) were used to describe and analyze the study variables and testing its hypotheses. The study occludes that it is possible to improve Jordanian the estimation efficiency of central government budget depending on information based on final account statement, with a high relative degree of importance. In light of this, the researcher recommends the necessity of depending greatly the central government on final account statement information showing among the recommendations depending greatly on final account statement justifications in improving Jordanian central government budget estimation.
\end{abstract}

Keywords: general budget, central government, final account statement, efficiency

\section{Introduction}

The general budget of the central government is considered one of the important tools used by general sector institutes to estimate central government incomes and spending for incoming time a year in general. These incomes and spending classification among groups or divisions or categories or items in order to be easily analyzed and to dealt with to fulfill different activities and programs directed by the government assuming that the budget is a future plan used as a planning and observational tool by most of governments in countries of the world (Halas, 2006, p. 131).

Due to the development of central government and the wide spread of economic planning and its curriculums and methods, the general budget has acquired a special importance. It became to represent the main financial plan to fulfill different developmental programs. This implies the availability of accounting information and data about these programs and the projects precisely for the central government to be able to compare the actual accounting incomes and spending of the budget with the general budget estimated spending to assess performance on different levels. So, the researcher studies this subject of final account statement from the (concept, aims, advantages, preparation stages, and constitutes) in addition to general budget of the central government from the concept (accounting, economical, planning legal, observational and political).In addition to the ways used to estimate budget numbers and to specify differential and similarities between the budget and final account statement, and finally to know the extent of possibility to depending on the information of the final account statement in improving estimation efficiency of Jordanian central government budget of Jordan central government. 


\subsection{Problem of the Study}

The researcher noticed that the estimation of Jordanian central government budget do not be on exact scientific bases, this makes it very difficult to act its role as a planning and observational tool. Ensuring this the estimations mentioned in the law of the general budget for the years (2010-2015) table 1 indicates this.

Table 1. Explains the ratio of ultimate incomes in summative spending

\begin{tabular}{llllll}
\hline 2010 & 2011 & 2012 & 2013 & 2014 & 2015 \\
\hline 81.7 & 79.7 & 73.5 & 81.4 & 92.5 & 94.1 \\
\hline
\end{tabular}

Resource: general financial bulletin (2015, p. 12).

Consequently, the study problem can be structured in the following two questions:

- Can the efficiency of the central government general budget estimation be improved depending on information based on final account statement?

- Are there significant moral differences between the views of different parts of the study sample concerning the general budget of Jordan central government estimation depending on information based on final account statement?

\subsection{Importance of the Study}

The importance of the study arouses as it is a scientific addition for the subject of governmental accounting because of the rarity of studies in this field. In addition, it tackles an important sector of Jordanian economical sectors represented in improving the estimation efficiency of the Jordanian central government budget.

\subsection{Objectives of the Study}

The main aim of the study lies in:

First: Recognizing information based on final account statement information and to the extent of depending on it in improving the estimation efficiency of Jordanian central government budget.

Second: Helping the central government administrations to make use of information based on final account statement which reflect positively on its performance in general and on the central government budget in precise through introducing recommendations based on this study results.

\section{Theoretical Frame of the Study}

\subsection{The Concept of Final Account Statement of the Central Government}

The second Article 2 of the Financial bylaw No (3) for the year (1994) and its modification has defined the final account as stating the budget accountings, and as a result of fulfilling over the meant financial year in accordance with the bases and criteria trusted in this bylaw and the laws and legislations. The final account can also be defined as stating the incomes of the government and their actual uses during the previous accounting period and what results as extra or shortage cash. (Ismail \& Adas, 2010, p. 471). Also, the government financial bulletin for the year $(2015$, p. 1) defined the central government as "represents all governmental ministries and departments that takes its budget from the law of general gadget of the state". Whereas the current study defines the final account statement of the central government as it is stated in the questionnaire items used in this study.

\subsubsection{Aims of Preparing Final Account Statement}

The final account reflects the result of the government financial performance as a whole since it summarizes the actual incomes and spending and financing resources in addition to showing general government surplus and shortage over the ended financial year (Ahmero, 2003, p.205). The aim of preparing the central government final account statement is to show its financial position and the results related to its administration of public cash through:

- Knowing the extent of efficiency in preparing central government general budget estimations and showing the government financial position. It shows the result of what has been achieved of surplus and shortage and the degree of capability of financial control through making sure that spending operations have been made according to allowances stated in the central government general budget. And that the spending operations have been made on the specified aims and making sure not to overcome the allowances stated in the law of the central government general budget. (Ismail \& Adas, 2010, p. 474) and (Al-Khatib \& Mahaini, 2008, p. 342). 
- $\quad$ Hijazi (2007, p.348) sees that final account statement enables to introduce government achievements and show the extent of stated and evaluate its performance in aims accomplishment in an accurate and actual way and final account is done in two stages, they are :

The first stage: subtracting real spending from real incomes to have surplus decrement of budget before financing.

The second stage: adding the result of the first stage whatever it was the surplus of finance, but if it was decrement, it added finance uses then we come up to the difference between the two sides which represents treasury surplus after finance or treasury unfinanced decrement.

From what precedes, the researcher notices the importance of final account_as control tool to know the extent of suitability of estimating incomes and spending ways, and improving them to get to as more and more accurate numbers.

\subsubsection{Final Account Elements}

Final account statement shows actual financial incomes and actual current spending for each financial year, also it indicates actual year saving (increasing actual incomes upon actual spending) or actual year decrement (increasing actual spending upon actual incomes). Also the final account indicates actual financial budget information (loan portions and due profits and their financial resources). Final account statement also shows the actual surplus or decrement after financing, the part of finance and resources are equal in final account statement (Abd -el Jaleel, 2008, p. 80).

Table 2.The elements of final account statement

\begin{tabular}{ll}
\hline Actual spending & Actual incomes \\
\hline Type of spending & Type of income \\
Current spending & Current incomes \\
Capital spending financed by treasury & Capital incomes \\
Capital spending financed by loans and donations & \\
Actual surplus & Actual decrement \\
Finance budget & \\
Finance resources & \\
Actual surplus & Actual decrement \\
Loans portions and profits paid & loans \\
Actual decrement after financing & Actual surplus after financing \\
Total & total \\
\hline
\end{tabular}

\subsection{The Concept of Central Government General Budget}

The second part of the general budget regulation law No (58) year (2008) defined the general budget of the central government as "the government plan for the next financial year to achieve the national aims in a medium range financial frame. The general budget of the central government is considered as a financial estimated plan the government expects containing spending and incomes of the state during the next period that is usually estimated a year, and expected to be approved by the national council. It is a document containing a detailed program for the government work (Ghura, 2016, p. 8).

The researchers investigated the concept of general budget of the central government in light of what is mentioned of different definitions whether they are from accounting view or economical or planning or legal or control or political that can be explained as following:

First: accounting concept of budget: which views the budget as accounting numbers representing portions that are expected to be spent and the incomes that are expected to be raised during a next period of a year (Salloum \& Mahaini, 2007, p. 96).

Second: The economical concept of the budget: The general budget includes the necessary programs to achieve the economical aims such as distributing state projects and the policies necessary to guide the national economy towards progress and increasing national product (Al-Khatib \& Mahaini, 2008, p. 274)

Third: planning concept of budget: The general budget can be viewed as a basic tool for planning as there is a relation between the estimations and the aims, the main activity becomes as analyzing the numbers in light of the 
general policies (Salloum \& Mahaini, 2007, p. 97).

Fourth: The legal concept of the budget: The general budget is considered as a legal document issued by the legislative authority and become obligatory to be fulfilled by all the departments of the state and its different institutions (Ismail \& Adas, 2010, p. 128).

Fifth: The control concept of the budget: The budget is considered as the general budget effective control tool by checking the accordance of actual execution of the assigned plans.in addition to studying the causes of deviation in fulfillment if they exist, and to take necessary procedures to correct mistakes and prevent reoccurrence (Yaghi, 2011, p. 446).

Sixth: the political concept of the budget: The general budget is a reflection of the financial, economical and political policy of the state. So, the legislative authority undertakes authorizing the executive authority to execute the general budget items of incoming and spending according to the general policy of the state (Mahmoud, 2011, p. 143).

According to what is previously above mentioned, the researcher can define the central general government budget as "a short range financial plan indicating the cost of the activities of governmental units during a coming financial year and its finance resources represented in numbers in a way that complies the needs of financial administration of the government from the data and information necessary to take decisions and delineate financial and economical policies, and setting the plans of economical development and evaluating efficiency and affectivity of performance.

\subsubsection{The Methods Used to Estimate Numbers of the General Central Government Budget}

The stage of preparation of the estimation of the next period is the one of the most important stage that the budget passes through. This is as the executive authority in Jordan preparing the central general government budget and make it ready as it is her responsibility for achieving the state aims and ability to put estimations and decide priorities from what information available about state financial and economical ability and its citizens needs efficiently. Efficiency means the ability to highlight the value and reduce expenses. It is not possible to achieve efficiency in case of only reducing expenses, but the two aims should be achieved together (Ashi, 2016, p. 12).

It is worth mentioning that there are many ways to estimate general incomes and sending of the central government can be specified as the following:

- The historical way (Automatic estimation way).This way suggests that what happened in the past will continue in the future. Up to this way, the actual sums are taken for incomes and spending that are evident in the final account for the ended financial year as estimations of the coming year budget. This way is distinguished of its simplicity and easiness and eliminating personal estimation (Hijazi, 2007, p. 89).

- The economical circulation way: According to this way, it depends on economical circulations that the economy passes through in both stagnation or prosperity in estimation of general incomes and spending (Hajjawi, 2004, p. 162).

- 3. The medial way: According to this way, the general incomes are estimated that are expected to be earned during the next financial year on bases of the medial of actual increase in incomes in specific previous years rating from three to five years (Ghura, 2016, p. 55).

- The direct estimation way: This way provides the specialized authority in estimating general incomes with the whole freedom to estimate the different expected incomes during the coming year and to depend on any method chosen to them to be guided with the incomes that are actually earned in the previous years, and what has been earned of incomes in the current year up to the time of preparing the estimations and the changes expected to happen next year (Ghura, 2016, p. 56).

Consequently, the researcher noticed there are many ways used to estimating the numbers of the central government general budget which urges from the central government to consider reality in estimating spending and incomes in the budget because the defects that occur in estimating spending and incomes will affect in a direct way on the result of the general budget for stagnation or surplus.

\subsubsection{The Similarities between Final Account and General Budget of Central Government}

Similarities between final account and general budget of central government are the following:

- Both of them include incomes and spending.

- The government represented in ministry of finance is specialized with preparing both of them. 
- One classification is followed in classifying general incomes and spending and final account (Ghura, 2016, p. 17).

\subsubsection{Differences between Final Account and Central General Government Budget}

Differences between final account and central general government budget are represented in the following:

- The numbers of the general budget related to incomes and spending are estimative, that is possibility, whereas the numbers of final account are actual for the incomes that are really earned, and the spending that are really spent.

- The general budget is prepared for a coming financial year but the final account is prepared for an ended year (Ghura, 2016, p. 17).

It is worth mentioning that what distinguishes this study upon other studies is that it came in the time of failure department of Jordan general budget in establishing accurate estimations for the central government budget for many following years. It also focused on improving efficiency of estimating Jordan general central government budget depending on information based on final account. Moreover, the study is distinguished for environment of its society sample, problem and questions it tackles and its variables and aim it searched for.

\section{Methodology of the Study}

In light of hypotheses this study aimed to test, the researcher collected data and analyzed them statistically using descriptive analytical approach as it is suitable to the study nature and its conditions and timing.

\subsection{The Model of the Study}

Figure 1 downward indicates the variables that the study includes, they are: independent variable represented in (final account statement information) and which is expected to have a role in (improving efficiency of central general government budget estimations) as dependent variable

$$
\text { Independent variable Dependent variable }
$$

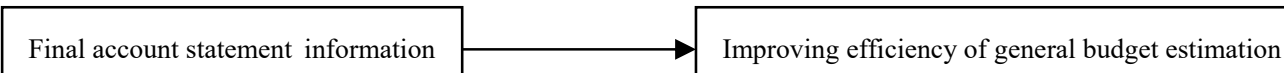

\subsection{Hypotheses of the Study}

The study depends on the following testing validity of hypotheses:

HO1: There is no role for information of final account statement in improving efficiency of estimating Jordan general government budget from the point of view of general budget department employees.

HO2: There are no significant differences to the role of information of final account statement in improving efficiency of estimating central Jordan general government budget due to demographic variables of general budget department employees.

\subsection{Data Collection Resources}

Necessary data for the study is obtained from two resources: the first is the secondary resource where data is by reviewing to what scientific books and magazines mentioned and internet sites and addition to governmental legislations of the study subject. The other resource is the primary resource that their basic data are obtained depending on the questionnaire designed especially for this study.

\subsection{Study Instrument}

A questionnaire is developed specially for this study depending on the theoretical frame and the previous studies consist of an introduction and two parts. The first part includes the special information of demographic variables of the study sample which are (gender, job title, experience, scientific qualification, scientific specialization).

The second part contains (11) questions aiming to study improving the efficiency of estimating central Jordan general government budget depending on final account statement information. To guarantee suitability of the tool of the study, to measure the aim that it is developed for, it has been changed into quantitative data using data as per Likert scale with its Five degrees and this scale will be dependent to test hypotheses according to the criteria explained in table3 down below which the study (Al- Hiyasat, 2013, p. 202) depended on. 
Table 3. Five point Likert scale

\begin{tabular}{lll}
\hline Effect degree & Weight & The importance according to medium \\
\hline Very big & (5) points & Very high \\
Big & (4) points & High \\
Medium & (3) points & Medium \\
Weak & (2) points & Low \\
No effect & (1) point & Very low \\
\hline
\end{tabular}

\subsection{Validation of Study Tool and Its Stability}

The study has been shown to (7) seven arbitrators of accounting and statistics professors in Jordanian universities, they present their views about how suitable the items of the study are. Omitting and modifications have been made to the questionnaire in light of the notes from them. This ensures external validity and content validity of the study tool. Also, stability coefficient (Cronbach Alpha) is computed to ensure internal consistency of the items of the questionnaire as it is the main study tool. The value of the coefficient was (\%87.2) and this is a high ratio for the aims of the study data analyses and testing its hypotheses (Guajarati, 2004, p. 359; Sekaran, 2010, p. 311).

\subsection{Community and Sample of the Study}

Study community consists of the ministry of Finance represented in the department of the general budget as it is the authority responsible for preparing the general budget of the state according to the law number (58) year (2008). Whereas the study sample consists the employees in the administrative and financial jobs, in addition to employees who work as budget analyst in the study community and there are (94) ninety four employees. The questionnaire has been distributed among them, the questionnaires that are regained are (63) which means (\%67.02) of the whole number of the distributed questionnaires, all of them have been statistically analyzed.

\subsection{Statistical Methods}

To accomplish the study aims and test its hypotheses, the researcher depended on many statistical methods in accordance with the nature of the study. Results have been obtained using Statistical Package for Social Science (SPSS).Statistical methods used as the following:

First: (Descriptive Statistical Measures) test to describe the characteristics of the study sample such as ; means, frequency, percentages and standard deviation

Second: (One Sample T-Test) to assure or negate the first hypothesis (HO1)

Third: (One Way ANOVA) test to assure or negate the second hypothesis (HO2)

Fourth: (Reliability Analysis Alpha) test to measure the degree of validity of the sample members responses of the study on the questionnaire items.

\section{Questionnaire Responses Analysis and Hypotheses Testing}

\subsection{Analyzing the Distribution of the Study Sample}

Analyzing the distribution of the study sample upon the personal and demographic characteristics of the study sample which is measured through questions number (1-5) from the questionnaire as indicated in tables (4-8).The results are as follows:

Table 4. Sample study distribution according to gender

\begin{tabular}{lll}
\hline Study category & Frequency & percentage \\
\hline Female & 8 & $\% 12.699$ \\
Male & 55 & $\% 87.301$ \\
Total & 63 & $\% 100$ \\
\hline
\end{tabular}

We can notice from the table 4 that the male category shaped the great with a ratio of (category of (\%87.301) whereas the female category has been a percentage of (\%12.699), and it is the smallest category of the sample of the study. This result explains the existence of positive effect multiple views of the study sample members. 
Table 5. Distributing members of the study sample according to job title

\begin{tabular}{lll}
\hline Study category & Frequency & percentage \\
\hline Administrative \& financial & 17 & $\% 26.984$ \\
Budget analyst & 46 & $\% 73.016$ \\
Total & 63 & $\% 100$ \\
\hline
\end{tabular}

We notice from Table 5 above that the smallest ratio of the study sample members are the administrative and financial, who are (17) with a ratio of (\%26.984) where the biggest ratio is for the budget analysts who are (46) which reached the ratio of (\%73.016). This result is explained with that the high ratio of budget analysts came natural as they are responsible for direct preparation supervision on the general budget of the central government.

Table 6. Distribution of study sample according to career experience

\begin{tabular}{lll}
\hline Study category & Frequency & Percentage \\
\hline 5 years and below & 9 & $\% 14.286$ \\
$6-10$ years & 14 & $\% 22.222$ \\
$11-15$ years & 16 & $\% 25.397$ \\
16 and more & 24 & $\% 38.095$ \\
Total & 63 & $\% 100$ \\
\hline
\end{tabular}

From the above table 6 we notice that the category of experience of (16 and more) has shaped the biggest category of the members of the study sample with a percentage of (\%38.095)whereas the percentage of experience of (11-15) years (\%25.397) and in the third place the percentage of (6-10) years with a percentage of $(\% 22.222)$, the category of (5 years and below) came in the final place with a percentage of $(\% 14.286)$.This result can explain that the availability of experience in this percentage has positive reflections on accomplishment of the aims of the study.

Table 7. Distribution of sample of the study according to scientific qualification

\begin{tabular}{lll}
\hline Study category & Frequency & Percentage \\
\hline Medium Diploma & 6 & $\% 9.524$ \\
Bachelor & 44 & $\% 69.841$ \\
High Diploma & 5 & $\% 7.936$ \\
Master and more & 8 & $\% 12.699$ \\
Total & 63 & $\% 100$ \\
\hline
\end{tabular}

The above table 7 shows that the category of bachelors has composed the biggest category of the members of the sample of the study with a percentage of $(\% 69.841)$ and the category of masters and more is in the second place with percentage of $(\% 12.699)$. In the third place, the category of Medium Diploma takes the percentage of $(\% 9.524)$ where the last place has gone to the category of High Diploma with a percentage of (\%7.936). This result can explain government sector tendency, in an increasing form to pinpoint the bachelors and more in the field of finance and supervision and so they can efficiently do the missions appointed to them

Table 8. Distribution of study sample on scientific specialization

\begin{tabular}{lll}
\hline Study category & Frequency & Percentage \\
\hline Accounting & 40 & $\% 63.492$ \\
Financial administration & 7 & $\% 11.111$ \\
Business administration & 10 & $\% 15.873$ \\
Other specializations & 6 & $\% 9.524$ \\
Total & 63 & $\% 100$ \\
\hline
\end{tabular}

We notice from the table above table 8 that biggest percentage of the sample of the study are accounting 
specialists (40) which means a percentage of (\%63.492), in the second rank, came the specialists of Business administration who are (10) with a percentage of (\%15.873), in the third rank came Financial administration

Specialists who are (7) with a percentage of (\%11.111). In the last rank, the other specialists who are (6) with a percentage of (\%9.524).This result explains the availability of suitable scientific specialization for the study sample members which enables them control the fulfillment of the central government general budget, and issuing periodical reports about following and analysis and evaluation.

\subsection{Study Hypotheses Testing}

\subsubsection{The First Hypothesis Questions}

Table 9 below indicates statistical average and standard deviation and relative percentage for each of question of the first hypothesis questions separately. They are tested through questions numbered (6-16) of the questionnaire. The results have been as the following:

Table 9. Statistical average, standard deviation and relative percentage for each of questionnaire items related to improving the efficiency of estimating general budget on the bases of final account statement

\begin{tabular}{|c|c|c|c|c|}
\hline Question no & Question & $\begin{array}{l}\text { Arithmetical } \\
\text { average }\end{array}$ & $\begin{array}{l}\text { Standard } \\
\text { deviation }\end{array}$ & Relative Importance \\
\hline 6 & $\begin{array}{l}\text { Final account statement helps indicate the state's } \\
\text { financial position }\end{array}$ & 4.76 & 0.81 & High \\
\hline 7 & $\begin{array}{l}\text { Information provided by the Final account statement } \\
\text { indicate the incomes and current spending accurately }\end{array}$ & 5 & 072 & Very high \\
\hline 8 & $\begin{array}{l}\text { Final account statement contributes to introduce } \\
\text { information help improve planning operation }\end{array}$ & 3.67 & 098 & Medium \\
\hline 9 & $\begin{array}{l}\text { Final account statement shows the actual capitalist } \\
\text { incomes and spending and their resources }\end{array}$ & 5 & 0.66 & Very high \\
\hline 10 & $\begin{array}{l}\text { Final account statement shows the surplus and } \\
\text { shortage in the central government general budget for } \\
\text { the year covered }\end{array}$ & 5 & 0.92 & Very high \\
\hline 11 & $\begin{array}{l}\text { Final account statement shows necessary financial } \\
\text { budget data }\end{array}$ & 4.86 & 1.08 & high \\
\hline 12 & $\begin{array}{l}\text { Final account statement enables analyzing activities } \\
\text { spending and general services that it fulfill }\end{array}$ & 4.40 & 0.76 & High \\
\hline 13 & $\begin{array}{l}\text { Final account statement is considered an active tool } \\
\text { helps improve estimation of central government } \\
\text { general budget preparation }\end{array}$ & 4.06 & 0.69 & High \\
\hline 14 & $\begin{array}{l}\text { Final account statement specify reasons of deviations } \\
\text { happen during general budget fulfillment, if there are } \\
\text { to avoid in the future }\end{array}$ & 4.24 & 1.03 & High \\
\hline 15 & $\begin{array}{l}\text { Final account statement help recognize the extent of } \\
\text { efficiency in estimating current general budget and } \\
\text { consequently work for improving its accuracy in the } \\
\text { future }\end{array}$ & 4.35 & 0.84 & High \\
\hline 16 & $\begin{array}{l}\text { Final account statement contributes in assessing } \\
\text { performance in respect of commitment to laws and } \\
\text { systems }\end{array}$ & 3.17 & 0.71 & Medium \\
\hline $6-16$ & All questions together & 4.41 & 0.85 & high \\
\hline
\end{tabular}

Data included in the table 9 to the point of view of the members of the study sample about the Final account statement and its role in improving the efficiency of estimations of central government general budget came with a degree of importance (very high, high, medium). Questions number (7) occupied the information provided by Final account statement showing the current incomes and spending accurately. Question number (9) that Final account statement shows that the real current capital incomes and spending and their resources. Question number (10) Final account statement shows the surplus or shortage in the general budget for the year it covers came in the first rank with a medium of (5) and standard deviation of $(0.92,0.72,0.66)$. Question number (16) that the 
Final account statement contributes in assessing performance in respect of commitment to laws and systems occupied the last rank with a medium of (3.17) and standard deviation of (0.71). Also, the responses of study sample were positive towards all questionnaire items. The general medium has reached (4.41) and standard deviation of (0.85) which is more than medium value of the measurement tool which is (3).This result explains the existence of harmony in point of views of the employees of the general budget department about information of final account statement and its role in improving the efficiency of central Jordan government budget estimations. The role of this information importance is relatively high.

\subsubsection{Testing First Hypothesis}

HO1: There is no role of the final account statement information in improving the efficiency of central Jordan government budget estimations from the view of general budget department employees

Table 10 shows results of (One Sample T- Test) to one sample of the first hypothesis on the level of value $(0.05 \geq a)$

Table 10. Results of (One Sample T- Test) for the first hypothesis

\begin{tabular}{llllllll}
\hline (T) computed & (T) scheduled & P- value & $\begin{array}{l}\text { Theoretical } \\
\text { medium }\end{array}$ & Medium & $\begin{array}{l}\text { Standard } \\
\text { deviation }\end{array}$ & $\begin{array}{l}\text { Degrees } \\
\text { freedom }\end{array}$ & of result \\
\hline 7.168 & 1.69 & 0.008 & 3 & 4.41 & 0.85 & 62 & refusal \\
\hline
\end{tabular}

Results of testing the first hypothesis indicate in table 10 above that the value of computed (T) equals (7.168) and it is higher than its scheduled value which equals (1.96). The value of (P- value) reached (0.008) and it is less than the value $(0.05 \geq a)$. As the base of decision is accepting the nil hypothesis if the value of computed (T) is less than scheduled value, and refusing nil hypothesis if the value of computed (T) is more than scheduled value. So, nil hypothesis is refused and accepting the substitute hypothesis which provided that there is a role of final account statement information in improving the efficiency of central Jordan government budget estimations from the views of employees of the general budget department. This study results agree with the results of (Ismail \& Adas, 2010) that point that final account statement Contributes to knowledge of the extent of the preparation of public budget studies. This study results agree with the results of each of (Hijazi, 2007) \& (Ahmero, 2003) that point that final account statement enables to evaluate government achievements and evaluate its performance in an accurate and realistic way.

\subsubsection{Second Hypothesis Testing}

HO2: There are no significant statistical differences of the role of final account statement information in improving the efficiency of central Jordan government budget estimations due to demographic variables of the employees of the general budget department. To check the validity of this hypothesis, variation analysis (ANOVA) is used where the results come up as shown in table 11.

Table 11. Results of test (One Way ANOVA) for the second hypothesis

\begin{tabular}{|c|c|c|c|c|c|}
\hline $\begin{array}{l}\text { demographic } \\
\text { variables }\end{array}$ & Freedom degree & (F)scheduled & (F) computed & SIG & result \\
\hline gender & 1 & 1.96 & 0.921 & 0.261 & Acceptance \\
\hline Job title & 1 & 1.96 & 0.319 & 0.120 & Acceptance \\
\hline Job experience & 3 & 1.96 & 0.328 & 0.803 & Acceptance \\
\hline $\begin{array}{l}\text { Scientific } \\
\text { qualification }\end{array}$ & 3 & 1.96 & 1.167 & 0.346 & Acceptance \\
\hline $\begin{array}{l}\text { Scientific } \\
\text { specialization }\end{array}$ & 3 & 1.96 & 0.615 & 1.201 & Acceptance \\
\hline
\end{tabular}

Results of testing the second hypothesis in table (11) above indicate that (F) computed value for all demographic variables is less than its scheduled value which equals (1.96) in value level $(0.05 \geq a)$.

As decision rule is the acceptance of nil hypothesis if (F) computed value is less than scheduled value, and refusing the hypothesis if (F) computed value is more than scheduled value. So, the substitute hypothesis is refused, and the nil hypothesis is accepted which suggests that there are no significant statistical differences of 
the role of final account statement information in improving the efficiency of central Jordan government budget estimations due to demographic variables of the employees of the general budget department. This result explains that information of final account statement has the same importance to all members of the study sample. This is because of their recognition of the importance of the role it plays in improving the efficiency of central government budget estimations.

\section{Conclusions and Recommendations}

After doing necessary and suitable statistical analyses, the researcher concludes that final account statement and the information it provides come after fulfilling central general government budget. This makes it a very important supervisional tool lead to evaluating the wholly financial performance of the central government accurately. This is through comparing actual performance of the budget with the planned performance, and limiting deviations and analyzing their causes. Consequently, it can be dependent to improving the efficiency of central Jordan government budget estimation. Moreover, final account statement information has the same importance for all members of the sample of the study. This is because of their recognition of the importance of the role it plays in improving the efficiency of Jordan central government budget estimations as it is based on real information that actually that have been done. In light of these conclusions, the researcher recommends the following:

- The necessity to depend on final account statement information in Jordan central government in amore and justified form, because depending on it helps indicate financial position of the government, and show current capitalist incomes and spending and their resources in an a curate form. It also indicates the surplus or the shortage in the general budget for the financial year it covers, and improving planning operation.

- The necessity to depend on final account statement information in Jordan central government in amore and justified form, because depending on it indicates necessary budget financial data, and analyzing activities spending and the different general services it fulfills. It also helps improve central government budget estimations. It contributes to performance evaluation of laws and legislations commitment. Finally, it helps define causes of deviations which helps recognize the efficiency in estimating central government current budget and to improve it accuracy in the future.

- The necessity to do more studies in the future about ways to improve efficiency of central government budget estimations where they are similar to this current study or completing or developing to it in governmental foundations that have financial and administrative independence.

\section{References}

Abd-el-Jaleel, T. (2008). Government Accounting (2nd ed.).Jordan University, Amman, Jordan.

Ahmrou, I. H. (2003). Government Accountability from Tradition to Modernity (1st ed.). Dar Al-Masirah for Publishing, Distribution and Printing, Amman.

Al-Hiyasat, H. (2013). Management incentives and its impact on the control procedures from the point of view of internal auditors in the public sector financial management in Jordan. IUG Journal of Economics \& Business, The Islamic University of Gasa, 21(2), 189-212.

Al-Khatib, K. S., \& Mahayni, M. K. (2008).Government Accounting ( $1^{\text {st }}$ ed.). Dar Wael for Publishing and Distribution, Amman, Jordan.

Ashi, B. (2016). The Quality of Information and Communication Technology and its Effect on the Efficiency of Internal Auditing at the National Institution for Well Works. Unpublished Master Thesis, Qasidi Marabah University, Wafralah, Algeria.

Ghura, F. A. K. (2016). The Statutory regulation of the Public Budget in Palestinian Legislation, Descriptive Analytical Study. Master Thesis Unpublished, Islamic University of Gaza.

Guajarati,D.N.(2004). Basic Econometrics (4th ed.). McGraw Hill, NewYourk,UNA.

Hajjawi, H. A. A. (2004). The Scientific and Practical Assets in Government Accounting (2nd ed.). Dar Hamed for Publishing and Distribution, Amman, Jordan.

Halas, S. A. (2006) The Role of Budgeting As a Tool for Planning and Control Tool in Palestinian Civil Society Organizations. Islamic University Journal (Series of Humanitarian studies). Islamic University of Gaza, 14(1), 154-311.

Hijazi, M. A. (2007). Government Accountability and Public Financial Management (7th ed.). Auther, Amman, Jordan. 
Ismail, I. K., \& Adas, N. H. (2010). Government Accounting. Dar Al Yazouri for Publishing and Distribution, Amman, Jordan.

Mahmoud, R.S. (2011). Government Accounting (1st ed.). Dar Al Masirah for Publishing and Distribution, Amman, Jordan.

Salloum, H. A. K., \&Muhaini, M. K. (2007).The State Budget between The Preparation, Implementation and Control. Journal of Administration and Economics, 64, 92-119.

Sekaran, U. (2010). Research Methods for Business: A skill Building Approach (5th ed.). John Wiley \& sons, Inc.

The Hashemite Kingdom of Jordan. (1994). Financial Bylaw.Official Newspaper. 3951.

The Hashemite Kingdom of Jordan. (2008). Budget Regulation Law. Official Newspaper. 4943.

The Hashemite Kingdom of Jordan. (2010). Budget Regulation Law. Official Newspaper. 5006.

The Hashemite Kingdom of Jordan. (2011). Budget Regulation Law. Official Newspaper. 5086.

The Hashemite Kingdom of Jordan. (2012). Budget Regulation Law. Official Newspaper. 5149.

The Hashemite Kingdom of Jordan. (2013). Budget Regulation Law. Official Newspaper. 5196.

The Hashemite Kingdom of Jordan. (2014). Budget Regulation Law. Official Newspaper. 5270.

The Hashemite Kingdom of Jordan. (2015). Budget Regulation Law. Official Newspaper.5333.

The Hashemite Kingdom of Jordan. (2015). Ministry Of Finance. General government Financial Bulletin, 17(1), $1-78$.

Yaghi, M. A. F. ( 2011). Principles of Public Administration (2nd ed.). Dar Wael for Publishing and Distribution, Amman, Jordan.

\section{Copyrights}

Copyright for this article is retained by the author(s), with first publication rights granted to the journal.

This is an open-access article distributed under the terms and conditions of the Creative Commons Attribution license (http://creativecommons.org/licenses/by/4.0/). 